\title{
The risk of HCV infection among health-care workers and its association with extrahepatic manifestations (Review)
}

\author{
ADRIANA GAROZZO $^{1 *}$, LUCA FALZONE $^{2 *}$, VENERANDO RAPISARDA $^{3}$, ANDREA MARCONI $^{3}$, \\ DIANA CINA ${ }^{4}$, CONCETTINA FENGA $^{5}$, DEMETRIOS A. SPANDIDOS ${ }^{6}$ and MASSIMO LIBRA ${ }^{2}$ \\ ${ }^{1}$ Section of Microbiology, Department of Biomedical and Biotechnological Sciences, University of Catania, I-95124 Catania; \\ ${ }^{2}$ Section of General, Clinical and Oncological Pathology, Department of Biomedical and Biotechnological Sciences, \\ University of Catania, I-95123 Catania; ${ }^{3}$ Section of Occupational Medicine, Department of Clinical and \\ Experimental Medicine, University of Catania; ${ }^{4}$ Department of Clinical Pathology, Garibaldi Hospital, I-9124 Catania; \\ ${ }^{5}$ Section of Occupational Medicine, Department of the Environment, Safety, Territory, Food and Health Sciences, \\ University of Messina, I-98125 Messina, Italy; ${ }^{6}$ Department of Virology, Faculty of Medicine, \\ University of Crete, Heraklion 71003, Crete, Greece
}

Received January 5, 2017; Accepted February 21, 2017

DOI: $10.3892 / \mathrm{mmr} .2017 .6378$

\begin{abstract}
Health care workers (HCWs) are frequently exposed to different biological agents during their activities and are frequently monitored. Among these infectious agents, human hepatitis $\mathrm{C}$ (HCV) can infect HCWs. In this review article, the risk of $\mathrm{HCV}$ infection among $\mathrm{HCWs}$ is discussed along with extrahepatic $\mathrm{HCV}$-related malignancies, such as non-Hodgkin lymphoma. Accidental contamination, represented by percutaneous and mucocutaneous infections is the main risk factor for such infection. The compliance of the protection procedures, included in the current regulation for HCWs, is the most important issue to reduce the risk of pathogen infections that in turn may produce reduction of infection-associated malignancies.
\end{abstract}

\section{Contents}

1. Introduction

2. HCV infection in health-care workers

3. HCV infection as a risk factor for lymphoma development

4. Conclusion

Correspondence to: Dr Massimo Libra, Section of General, Clinical and Oncological Pathology, Department of Biomedical and Biotechnological Sciences, University of Catania, Torre Biologica, Via Santa Sofia 97, I-95123 Catania, Italy

E-mail: m.libra@unict.it

${ }^{*}$ Contributed equally

Key words: health-care workers, human hepatitis C, biological risk, lymphoma, occupational exposure

\section{Introduction}

Many professional activities expose workers to several biological agents representing a consistent risk factor for the development of infective and non-infective pathologies. Among these activities, including different professional areas such as agriculture, breeding of livestock, food industry and biotechnology, the most dangerous biohazard is the health-care associated activity. Because of the intrinsic purpose of hospital workplace, health care workers (HCWs) may be exposed to biological agents. Accordingly, HCWs are frequently controlled and monitored because of the high risk of biological contamination during their activities (1). It was assessed that the biological risk in workplaces is responsible for $>300,000$ deaths per year worldwide underlining the importance of the development of new monitoring strategies and approaches to prevent the spread of contamination in indoor and closed workplaces, such as hospitals (2).

One of the main sources of nosocomial biohazard contamination are the bio-aerosols containing a plethora of microorganisms, including endotoxins and molds, able to determine infections in both patients and HCWs through their inhalation $(3,4)$. Another source of contamination, especially for viral infections, may occur by direct exposure to biological fluids, including blood, urine, semen and cerebral spinal fluid (5). Unfortunately, this contamination is often linked to percutaneous transmission occurring after needle-stick injuries or cuts with other sharp instruments (6).

Several microorganisms such as Pseudomonas aeruginosa, Pseudomonas spp, Staphylococcus aureus, Staphylococcus epidermidis, Acinetobacter, Enterobacter, Enterococcus and Legionella can infect HCWs in different hospital environments $(7,8)$. The infections due to these bacteria are particularly difficult to eradicate because the infectious agent may acquire different mechanisms of resistance for which the use of the common antibiotic therapy is ineffective. One study has shown how in these cases the use of drugs such as netilmicin is able 
A

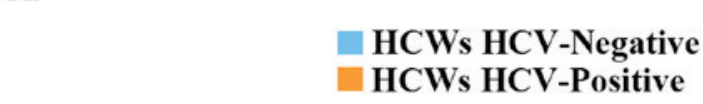

B

Nurses

Physicians and Surgeons Others

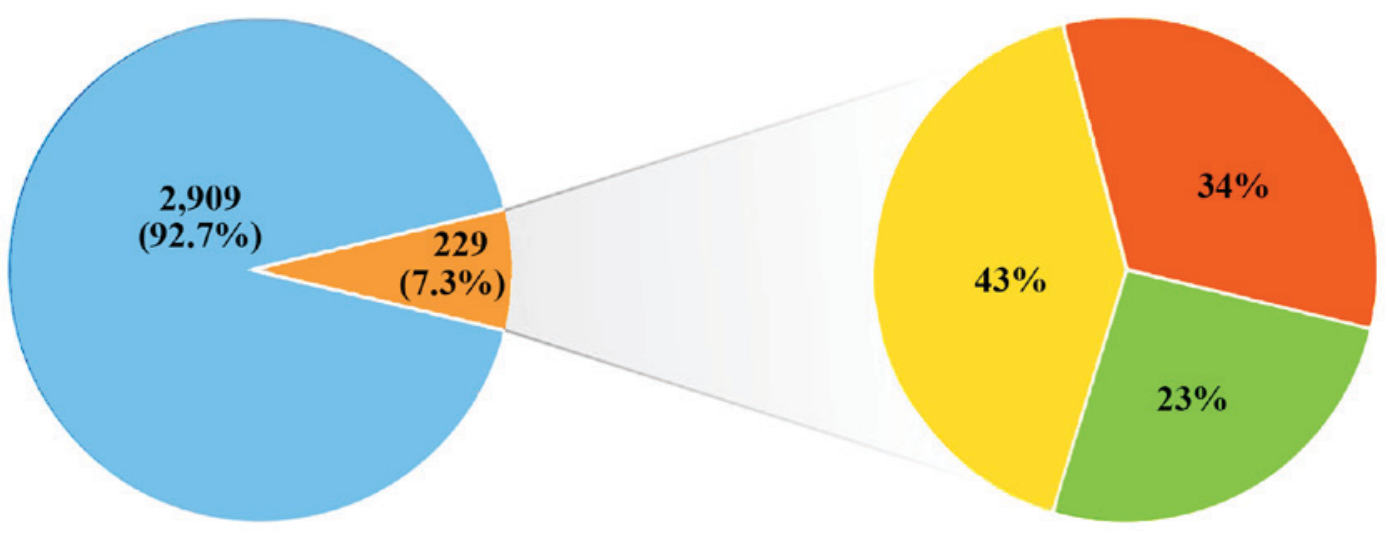

Figure 1. HCV infection status among HCWs according to the previous experience by Rapisarda et al, 2013 (21). (A) Frequency of HCWs with and without $\mathrm{HCV}$ infection; (B) Distribution of HCV-infected HCWs according to professional category. HCWs, health care workers; HCV, human hepatitis C.

to reduce the adhesiveness, hydrophobic interactions, fimbriation or motility of the bacteria, although it is not able to kill them, thus reducing the risk of infections or the development of severe infectious diseases (9).

HCWs can also be infected by several viruses. Many of these may cause neoplastic transformation and are recognized as 'carcinogenic to human (group 1) by the International Agency for Research on Cancer (IARC)'. Among these, Epstein-Barr virus (EBV), hepatitis B and $\mathrm{C}$ viruses (HBV and HCV), human T-cell lymphotropic virus type 1 (HTLV-1), human herpes virus type $8(\mathrm{HHV}-8)$ and human papillomavirus (HPV) are the most common viruses responsible for cancer development after chronic infection (10-17). The discovery of novel antiviral therapies, including that for $\mathrm{HCV}$ infection (18), may reduce the development of many cancer types. Based on the above, our research group investigated the antiviral and antiproliferative effects of novel compounds belonging to the class of $\mathrm{C}$-nucleosides showing encouraging results for the treatments of cancer, especially in the context of viral infections (19).

Our previous studies described the frequency of $\mathrm{HCV}$ infection among HCWs and a case of non-Hodgkin lymphoma was diagnosed during the survey $(20,21)$. According to this observation, in the present review, $\mathrm{HCV}$ infection among HCWs is analyzed taking into account the association with lymphoma development.

\section{HCV infection in health-care workers}

Several studies show that a correct knowledge and training of health-care workers significantly reduces the risk of accidental exposure to biological agents. Notably, the frequency of accidental exposure to biohazard agents increases among workers with less working seniority, such as nursing students or trainees, compared to the older workers (22-24). Conversely, other studies showed that workers with $>15$ years professional experience had an incidence rate for accidental contamination three times higher than workers with a work experience $\leq 5$ years (25). These data may be due to a more prolonged exposure to biological risk in workers with higher work experience and not to the inexperience of the workers (26-28).

The most common mode of transmission of HBV and $\mathrm{HCV}$, during health-care work activities, is due to percutaneous exposure and sharp injuries (29-31). Of note, many $\mathrm{HCV}$ infected patients do not show severe clinical manifestations and do not reveal their infection status to HCWs. Accordingly, the accidental contact with the infected material was previously very common. In fact, the World Health Organization (WHO) stated that in the European area only the percutaneous exposure risk of $\mathrm{HBV}$ and $\mathrm{HCV}$ infections in the health-care workers is $>450,000$ cases of which 340,000 for HBV virus and 149,000 for HCV (31-33). According to the current regulation, caution by all $\mathrm{HCW}$ have to be applied with the patients with and without any diagnosed infections.

Our research group conducted a 10 -year observational study to determine the frequency of HCV infection among HCWs from a single institution. This study included a case series of 403 workers employed in various clinical areas. This study showed that the high prevalence of HCV infection was found in nurses (3\%) and physicians/surgeons (5\%) in comparison to the other health-care worker categories. An important result of the study was that in the 10-year survey there were no new infections by HCV in the monitored workers. This result stresses the concept that the correct handling procedures of hazardous biological materials and the use of personal protective equipment lead to a reduction or a total avoidance of the risk of infection due to biohazard materials $(20,34)$. Therefore, these data are in agreement with previous studies demonstrating that the education of workers employed in hospitals or laboratories on the prevention of needle-stick accidents or sharp injuries is able to decrease needle-stick injuries (35-37). The cross contamination occurred between infected patients and health-care workers and vice versa could be avoided wearing protective barriers (gloves and lab coat), washing hands frequently and taking care in using biological materials, needles or sharp objects. The use of written protocols and standard procedures is certainly a good strategy that allows to minimize the risk of accidental infection caused by $\mathrm{HCV}$ 
and other hazardous biological agents with which workers may come into contact in hospitals $(38,39)$.

\section{HCV infection as a risk factor for lymphoma development}

It is already known that HCV infection promotes hepatic $(40,41)$ and extra-hepatic diseases including vascular and musculoskeletal disorders (e.g., cryoglobulinemia, arthralgia and myalgia), cardiovascular, renal, autoimmune and B-cell lymphoproliferative diseases (42-49).

In our experience, the above mentioned 10-year study, revealed that one of the $\mathrm{HCV}$-infected $\mathrm{HCWs}$, with a chronic infection history of 25 years, developed a mucosa-associated lymphoid tissue lymphoma (MALT) of the liver (20). Molecular analyses of tumor tissue indicated that immunoglobulin gene combinations were those usually detected among HCV-associated lymphomas (11). Furthermore, the discovery of MALT lymphoma with the concomitant $\mathrm{HCV}$ infection prompted us to extend the investigation to a larger cohort of HCWs. Thus, a tailored health surveillance program to 3,138 health-care workers employed in four Italian medical institutions was applied (21). Of these, 1,352 (43\%) were nurses, $953(30 \%)$ were physicians and surgeons and $833(27 \%)$ were other employees working in medical institutions. All the workers were screened for HCV infection by anti-HCV antibodies. HCV infection was detected in 229 out of $3,138 \mathrm{HCWs}(7.3 \%)$. Of the HCV-infected HCWs, $43 \%$ were nurses, $34 \%$ physician and surgeons and $23 \%$ were other employees (Fig. 1). Intriguingly, a case of gastric Malt lymphoma was observed among those with HCV infection (21). As revealed in the previous independent survey of HCWs by Marconi et al, 2010, the molecular analyses performed in such Malt tumor tissue supported the notion that HCV infection was associated with the malignant transformation (20).

\section{Conclusions}

Health-care professionals are a working category particularly exposed to biological risk factors during the normal working activities. These workers are daily subjected to occupational biological exposure in handling blood-borne samples or other biological fluids. One of the main sources of accidental contamination is represented by percutaneous and mucocutaneous infections (24). Microorganisms contained in aerosols, aerial dissemination caused by ventilation systems and direct infection with affected patients represent other ways of contamination (50). The application of the standard precautions during work activities is the most important reason in reducing the risk of blood-borne pathogen transmission that in turn may result in reduction of infection-related cancers.

\section{References}

1. Messineo A and Marsella LT: Biological hazards and healthcare-associated infections in Italian healthcare facilities: Some considerations on inspections and accountability. Ann Ig 27: 799-807, 2015.

2. Corrao CR, Mazzotta A, La Torre G and De Giusti M: Biological risk and occupational health. Ind Health 50: 326-337, 2012.

3. Srikanth P, Sudharsanam S and Steinberg R: Bio-aerosols in indoor environment: Composition, health effects and analysis. Indian J Med Microbiol 26: 302-312, 2008.
4. Heimbuch BK, Wallace WH, Balzli CL, Laning ML, Harnish DA and Wander JD: Bioaerosol exposure to personnel in a clinical environment absent patients. J Occup Environ Hyg 13: D11-D15, 2016.

5. Tarantola A, Abiteboul D and Rachline A: Infection risks following accidental exposure to blood or body fluids in health care workers: A review of pathogens transmitted in published cases. Am J Infect Control 34: 367-375, 2006.

6. Castella A, Vallino A, Argentero PA and Zotti CM: Preventability of percutaneous injuries in healthcare workers: A year-long survey in Italy. J Hosp Infect 55: 290-294, 2003.

7. Pierce GE: Pseudomonas aeruginosa, Candida albicans, and device-related nosocomial infections: Implications, trends, and potential approaches for control. J Ind Microbiol Biotechnol 32: 309-318, 2005.

8. Beggs CB, Kerr KG, Noakes CJ, Hathway EA and Sleigh PA: The ventilation of multiple-bed hospital wards: Review and analysis. Am J Infect Control 36: 250-259, 2008.

9. Furneri PM, Garozzo A, Musumarra MP, Scuderi AC, Russo A and Bonfiglio G: Effects on adhesiveness and hydrophobicity of sub-inhibitory concentrations of netilmicin. Int J Antimicrob Agents 22: 164-167, 2003.

10. Shinozaki-Ushiku A, Kunita A and Fukayama M: Update on Epstein-Barr virus and gastric cancer (Review). Int J Oncol 46: 1421-1434, 2015.

11. Libra M, Gloghini A, De Re V, Rupolo M, Navolanic PM, Gasparotto D, Stivala F, Spina M, Boiocchi M and Carbone A: Aggressive forms of non-Hodgkin's lymphoma in two patients bearing coinfection of Epstein-Barr and hepatitis $\mathrm{C}$ viruses. Int $\mathrm{J}$ Oncol 26: 945-950, 2005.

12. Gloghini A, Gaidano G, Larocca LM, Pierconti F, Cingolani A, Dal Maso L, Capello D, Franceschi S, Tirelli U, Libra M, et al: Expression of cyclin-dependent kinase inhibitor $\mathrm{p} 27^{\mathrm{Kip} 1}$ in AIDS-related diffuse large-cell lymphomas is associated with Epstein-Barr virus-encoded latent membrane protein 1. Am J Pathol 161: 163-171, 2002.

13. Arzumanyan A, Reis HM and Feitelson MA: Pathogenic mechanisms in HBV- and HCV-associated hepatocellular carcinoma. Nat Rev Cancer 13: 123-135, 2013.

14. De Re V, Caggiari L, De Zorzi M, Repetto O, Zignego AL, Izzo F, Tornesello ML, Buonaguro FM, Mangia A, Sansonno D, et al: Genetic diversity of the KIR/HLA system and susceptibility to hepatitis C virus-related diseases. PLoS One 10: e0117420, 2015.

15. Beral V, Peterman T, Berkelman R and Jaffe H: AIDS-associated non-Hodgkin lymphoma. Lancet 337: 805-809, 1991

16. Libra M, Scalisi A, Vella N, Clementi S, Sorio R, Stivala F, Spandidos DA and Mazzarino C: Uterine cervical carcinoma: Role of matrix metalloproteinases (Review). Int J Oncol 34: 897-903, 2009.

17. Petry KU: HPV and cervical cancer. Scand J Clin Lab Invest Suppl 244: 59-62, 2014.

18. Ewers EC, Shah PA, Carmichael MG and Ferguson TM: Concurrent systemic chemoimmunotherapy and sofosbuvir-based antiviral treatment in a hepatitis $C$ virus-infected patient with diffuse large B-cell lymphoma. Open Forum Infect Dis 3: ofw223, 2016.

19. Giofrè SV, Romeo R, Carnovale C, Mancuso R, Cirmi S, Navarra M, Garozzo A and Chiacchio MA: Synthesis and biological properties of 5-(1H-1,2,3-triazol-4-yl)isoxazolidines: A new class of $C$-nucleosides. Molecules 20: 5260-5275, 2015.

20. Marconi A, Candido S, Talamini R, Libra M, Nicoletti F, Spandidos DA, Stivala F and Proietti L: Prevalence of hepatitis C virus infection among health-care workers: A 10-year survey. Mol Med Rep 3: 561-564, 2010.

21. Rapisarda V, Marconi A, Candido S, Nicolosi D, Salmeri M, Gangemi P, Proietti L, Spandidos DA, Bracci M, Fenga C, et al: A tailored health surveillance program unveils a case of MALT lymphoma in an HCV-positive health-care worker. Oncol Lett 5: 651-654, 2013.

22. Maniar HH, Tawari AA, Suk M, Bowen TR and Horwitz DS: Percutaneous and mucocutaneous exposure among orthopaedic surgeons: Immediate management and compliance with CDC protocol. J Orthop Trauma 29: e391-e394, 2015.

23. Mohammadi N, Allami A and Malek Mohamadi R: Percutaneous exposure incidents in nurses: Knowledge, practice and exposure to hepatitis B infection: Percutaneous exposure incidents in nurses. Hepat Mon 11: 186-190, 2011.

24. Petrucci C, Alvaro R, Cicolini G, Cerone MP and Lancia L: Percutaneous and mucocutaneous exposures in nursing students: An Italian observational study. J Nurs Scholarsh 41: 337-343, 2009. 
25. Kosgeroglu N, Ayranci U, Vardareli E and Dincer S: Occupational exposure to hepatitis infection among Turkish nurses: Frequency of needle exposure, sharps injuries and vaccination. Epidemiol Infect 132: 27-33, 2004.

26. Alese OO, Alese MO, Ohunakin A and Oluyide PO: Seroprevalence of hepatitis B surface antigen and occupational risk factors among health care workers in Ekiti State, Nigeria. J Clin Diagn Res 10: LC16-LC18, 2016.

27. Chiarakul S, Eunumjitkul K, Vuttiopas S, Vorapimol AR, Kaewkungwal J and Poovorawan Y: Seroprevalence and risk factors of hepatitis B virus infection among health care workers at the Institute of Neurology. J Med Assoc Thai 90: 1536-1545, 2007.

28. Ciorlia LA and Zanetta DM: Hepatitis B in healthcare workers: Prevalence, vaccination and relation to occupational factors. Braz J Infect Dis 9: 384-389, 2005.

29. Mischke C, Verbeek JH, Saarto A, Lavoie MC, Pahwa M and Ijaz S: Gloves, extra gloves or special types of gloves for preventing percutaneous exposure injuries in healthcare personnel. Cochrane Database Syst Rev 3: CD009573, 2014.

30. Mbaisi EM, Ng'ang'a Z, Wanzala P and Omolo J: Prevalence and factors associated with percutaneous injuries and splash exposures among health-care workers in a provincial hospital, Kenya, 2010. Pan Afr Med J 14: 10, 2013.

31. Prüss-Ustün A, Rapiti E and Hutin Y: Estimation of the global burden of disease attributable to contaminated sharps injuries among health-care workers. Am J Ind Med 48: 482-490, 2005.

32. Westermann C, Peters C, Lisiak B, Lamberti M and Nienhaus A: The prevalence of hepatitis $\mathrm{C}$ among healthcare workers: A systematic review and meta-analysis. Occup Environ Med 72 880-888, 2015.

33. Prüss-Ustün A, Rapiti E and Hutin Y: Sharp injuries: Global burden of disease from sharp injuries to health-care workers. Environmental Burden of Disease Series, No. 3. Prüss-Üstün A Campbell-Lendrum D, Corvalán C, Woodward A (eds). World Health Organisation, Geneva, 2003.

34. Proietti L, Malaponte G, Libra M, Navolanic PM, Bevelacqua Y, Travali S and Mazzarino MC: Analysis of hepatitis C virus infection among health-care workers: An observational study. Minerva Gastroenterol Dietol 51: 255-259, 2005.

35. Haiduven DJ, Phillips ES, Clemons KV and Stevens DA: Percutaneous injury analysis: Consistent categorization, effective reduction methods, and future strategies. Infect Control Hosp Epidemiol 16: 582-589, 1995

36. Tarigan LH, Cifuentes M, Quinn M and Kriebel D: Prevention of needle-stick injuries in healthcare facilities: A meta-analysis. Infect Control Hosp Epidemiol 36: 823-829, 2015.

37. De Carli G, Abiteboul D and Puro V: The importance of implementing safe sharps practices in the laboratory setting in Europe. Biochem Med (Zagreb) 24: 45-56, 2014.
38. Davanzo E,Frasson C,Morandin M and Trevisan A: Occupational blood and body fluid exposure of university health care workers. Am J Infect Control 36: 753-756, 2008.

39. van Gemert-Pijnen J, Hendrix MG, Van der Palen J and Schellens PJ: Effectiveness of protocols for preventing occupational exposure to blood and body fluids in Dutch hospitals. J Hosp Infect 62: 166-173, 2006.

40. Denniston MM, Jiles RB, Drobeniuc J, Klevens RM, Ward JW, McQuillan GM and Holmberg SD: Chronic hepatitis C virus infection in the United States, National Health and Nutrition Examination Survey 2003 to 2010. Ann Intern Med 160: 293-300, 2014.

41. Bartosch B, Thimme R, Blum HE and Zoulim F: Hepatitis C virus-induced hepatocarcinogenesis. J Hepatol 51: 810-820, 2009.

42. Taborelli M, Polesel J, Montella M, Libra M, Tedeschi R, Battiston M, Spina M, Di Raimondo F, Pinto A, Crispo A, et al: Hepatitis $\mathrm{B}$ and $\mathrm{C}$ viruses and risk of non-Hodgkin lymphoma: A case-control study in Italy. Infect Agent Cancer 11: 27, 2016.

43. Cacoub P, Commarmond C, Sadoun D and Desbois AC: Hepatitis $C$ virus infection and rheumatic diseases: The impact of direct-acting antiviral agents. Rheum Dis Clin North Am 43: 123-132, 2017.

44. Cacoub P, Comarmond C, Domont F, Savey L, Desbois AC and Saadoun D: Extrahepatic manifestations of chronic hepatitis C virus infection. Ther Adv Infect Dis 3: 3-14, 2016.

45. Terrier B and Cacoub P: Renal involvement in HCV-related vasculitis. Clin Res Hepatol Gastroenterol 37: 334-339, 2013.

46. Aslam F, Alam M and Lakkis NM: Hepatitis C and carotid atherosclerosis: A retrospective analysis. Atherosclerosis 209: 340-343, 2010.

47. Libra M, Polesel J, Russo AE, De Re V, Cinà D, Serraino D, Nicoletti F, Spandidos DA, Stivala F and Talamini R: Extrahepatic disorders of HCV infection: A distinct entity of B-cell neoplasia? Int J Oncol 36: 1331-1340, 2010.

48. Libra M, Gloghini A, Malaponte G, Gangemi P, De Re V, Cacopardo B, Spandidos DA, Nicoletti F, Stivala F, Zignego AL, et al: Association of $\mathrm{t}(14 ; 18)$ translocation with HCV infection in gastrointestinal MALT lymphomas. J Hepatol 49: 170-174, 2008.

49. Libra M, Gasparotto D, Gloghini A, Navolanic PM, De Re V and Carbone A: Hepatitis C virus (HCV) I hepatitis C virus (HCV) infection and lymphoproliferative disorders. Front Biosci 10: 2460-2471, 2005

50. Beggs C, Knibbs LD, Johnson GR and Morawska L: Environmental contamination and hospital-acquired infection: Factors that are easily overlooked. Indoor Air 25: 462-474, 2015. 